\title{
PREECLAMPSIA AND ITS CORRELATION WITH INFANT MORTALITY: A META-ANALYSIS
}

\author{
Ruth Apriyanti \\ Masters Program in Public Health, Universitas Sebelas Maret
}

\begin{abstract}
Background: Management of preeclampsia often culminates in induced delivery of a preterm infant. While early termination protects the fetus from an intrauterine death, the newborn then faces increased risks associated with preterm delivery. Recent evidence suggests that preeclampsia is a major cause of perinatal morbidity and death. This study aimed to explore correlation between preeclampsia and infant mortality.

Subjects and Method: A systematic review and meta analysis was conducted using the Pubmed, Google Scholar, and Science Direct databases, published from 2011 to 2021. Eligibility criteria were defined using the PICO model as follows, (1) population: pregnant women, (2) intervention: preeclampsia, (3) comparison: without preeclampsia, and (4) outcome: infant mortality. The following search terms were used: "Preeclamsia" OR "Preeclampsia" AND "Perinatal Death" OR "Perinatal Mortality" OR "Fetal Death" AND "Pregnancy, High-Risk" OR "Pregnancy" OR "Pregnant Women". The inclusion criteria were English full-text, cohort study, and reported adjusted Odds Ratio (aOR). The systematic review was carried out according to the PRISMA guidelines. Data analyses were performed using RevMan 5.3.

Results: A total of 7 articles from China, Israel, Netherlands, Norway, and United States were eligible for quantitative meta-analyses. This study showed that preeclampsia elevated the risk of infant mortality $(\mathrm{aOR}=1.95 ; 95 \% \mathrm{CI}=1.22$ to $3.11 ; \mathrm{p}=$ 0.005).
\end{abstract}

Conclusion: Preeclampsia elevates the risk of infant mortality.

Keywords: preeclampsia, perinatal death, fetal death, infant mortality

\section{Correspondence:}

Ruth Apriyanti. Masters Program in Public Health, Universitas Sebelas Maret. Jl. Ir. Sutami 36A, Surakarta 57126, Central Java. Email: ruthyanti94.ras@student.uns.ac.id. Mobile: 081375232120. 